\section{ON \\ A NEW OPERATION FOR CANCER OF THE BREAST.}

By RICHARD SWEETING, M.D., M.R.C.S.E.

THE ordinary operation for cancer of the breast is so unfortunate that many good surgeons reprobate it altogether. The disease so generally returns that some of our authorities approve of operating on account of the interval of ease between the time of the operation and the period of return; estimating that, whether you operate or not, your patient will die at about the same future period of from six to eighteen months. If you do not remove the breast, she suffers all the time. If you do remove the breast, she has the luxury of some six or eight months' ease; then the cancer returns, and advances very rapidly.

Occasionally you make a very good case, and the cancer does not return. Paget says it generally returns in six months; but that the patient may be considered safe in those very rare cases in which the scar left by operation is soft and sound after fourteen months. This result is so rare that many experienced hospital surgeons have never seen it. Such is the result after the usual operation for scirrhous mamma.

If the disease returns so frequently why not cut deeper? You come on the fascia of the pectoralis major; your patient can do well without it. All return of purely local cancer must depend on amorphous cancer-cells not removed by previous operations; and as it begins in this fascia, how strange it is that nobody removes it. We can hardly admit that cancer-cells can lie only on the fascia without imbedding themselves in the lower part of the pectoralis major, which is certainly not a vital organ that can be safely removed. The lower two-thirds of the muscle is more than occupied by the base of a large cancer. So much being lost from the muscle, its action is adequate for all ordinary purposes for which muscular action is used by the invalid matrons who are generally the victims of cancer. Such an operation should be preliminated by the usual incisions over the breast; but they should remove a much larger portion of skin, so that a very little subcutaneous incision shall lay bare the edge of the pectoralis major towards the axilla and its attachments towards the sternum. Instead, therefore, of removing the breast from the fascia, the proposal is to remove the lower two-thirds of the pectoralis major, and all that is above it except a portion of the skin. The surgical anatomist can readily see that you do not by these incisions add to the danger of the operation.

My object in sending this paper to THE LANCET is to say that I have operated in this way in three different cases, and with permanent success in each case.

CASE 1.-Mrs. C- aged fifty-nine, a sickly, delicate woman, was operated on about six years ago. She bore the operation well, and the wound healed readily. She died of bronchitis two years and one month after the operation. There was not the slightest trace of the return of cancer.

CASE 2.-Mrs. R—, aged fifty-four. In this case, also, we had the best possible results. The cancer had not returned after two years and seven months, when I saw her last.

In the third case the cancer was removed by this mode of operating in September, 1868. The patient has done well, the wound having healed without a trace of cancerous induration, and I think it safe from a return of the disease.

In all these cases the hæmorrhage was very slight. It is fair to say that we have thus, in the only cases treated on this plan, no return of this terrible malady. We must not be too sanguine, the number being very small; but it is more promising to have three good cases out of only three operations than to operate on the old plan on hundreds of cases without one good result beyond a few months' ease. Some of our hospital surgeons may think the plan deserves a more extended trial. When we recall what we have all seen of this dreadful disease, it is only human charity to hope that we have not done all that can be done.

We are told " that it would be madness and inconsistency to suppose that things which have never yet been done can be performed without employing some hitherto untried means." We have never yet in any other way operated for cancer of the breast with a reasonable prospect of its not returning. The senior surgeon of a county hospital was present and assisted in one of these operations, and when it was over said most emphatically, "That will never return." I have it from good authority that no case can be named of permanent success in the cases turned cut from this very hospital, although its surgeons are very able men. Let us hope that "what is worst in regard to the past may appear more consolatory for the future." ("Novum Organum," Bk. I., xciv.) It would be indecorous to the present logical merits of surgical science, and would imply a hope too strong to be reasonable, if I were to quote the rest of the paragraph. But, after all, the ounce of mother wit may more than equipoise the pound of College; for if a purely localised cancer is to be cured by incisions, and is sure to return if not completely removed, then we are more likely to succeed in proportion as our incisions are as deep and as extensive as is consistent with the patient's safety. Stratford, February, 1869.

ON THE

\section{ADMINISTRATION OF HYPOSULPHITE OF SODA IN AGUE AND TYPHOID FEVER.}

BY T. F. SANGER, M.R.C.S.,

SURGgON TO THB CONVALESCENT HOSPITAL, SEA YORD.

The theory of the cause of ague and typhoid fever being due to the germs of a fungus having entered the system appears to me to be proved by the following cases.

In the spring of 1868, I had a very intractable case of ague in a boy eleven years of age, which resisted all the remedies usually employed in the treatment of that disease, these being given until the boy said his stomach could not bear any more. Following out the fungus theory, I gave the patient a scruple of the hyposulphite of soda three times a day, which in a very few days got rid of the ague, and he has never had it since.

In the autumn, three sisters and the mother of the lad became the victims of a very bad tertian ague, which resisted the administration of emetics, quinine, bebeerine, and arsenical solution, but gave way to a very few doses of the hyposulphite of soda.

I have since tried the hyposulphite in a few cases of typhoid fever, and with beneficial results similar to those attributed to the sulphurous acid by Mr. Robert Hamilton. in a paper on Typhoid Fever in The LanCET of Jan. 9th.

The hyposulphite of soda I administer in doses of from fifteen to thirty grains three or four times a day (according to the ages of the patients), in water, with syrup of lemons or tolu. It does not produce any nausea or relax the bowels.

I mean to administer the hyposulphite of soda in large and frequent doses to the next patient I have with diphtheria, and anticipate similar favourable results.

Alfriston, Seaford, Jan. 24th, 1869 .

Bromide of Potassium in Epilepsy - Fatal EFFECTS of Tartar EMetic.-The last number of the Reports of the Medico-Chirurgical Society of Bordeaux states that an epileptic woman, who took for one year bromide of potassium, in doses varying from thirty grains to an ounce per diem, at last fell a victim to the debilitating effects of this salt, and died in a state of prostration. The same paper mentions a case in which three-fourths of a grain of tartarised antimony, given in three tumblers of water, produced severe sickness, weakness of pulse, hiccup, gradual sinking, and death in thirty-six hours. M. Chereau, who mentions the case in L'Union Médicale of Jan. 21st, gives neither the age nor the sex of the patient.

Glasgow Medical Association.-The annual meeting for the election of office-bearers was held at the Waverley Hotel, on the 11th ult., when the following appointments were made:-President: John Reid. Vicepresident: John Dougan. Secretaries: George McGregor, M.D., J. B. Hislop. Treasurer : R. Grieve. 